\title{
A Framework for Analyzing Information Flows in Public Policy Decision-making: A Move towards Building Sustainable Policy Instruments
}

\author{
Chad McGuire (Corresponding author) \\ Department of Public Policy, University of Massachusetts, Dartmouth \\ 285 Old Westport Road, Dartmouth, Massachusetts 02747, United States \\ Tel: 1-508-999-8520_E-mail: cmcguire@umassd.edu
}

Received: January 26, 2011

Accepted: March 1, 2011

doi:10.5539/jpl.v4n2p25

\begin{abstract}
The purpose of this paper is to explain a framework that focuses on information flows as a means of understanding public policy decision-making, with a specific emphasis on information relating to sustainable development. The goal of this framework is to further aid in identifying and explaining the extent to which sustainability goals are being implemented in public policy decisions. The suggestion is that by focusing on the information flows directly related to sustainable information, instances can be isolated where specific pieces of information are not making their way to final decision-making processes, or alternatively, where new information interferes with sustainable information becoming part of the final decision-making process. This paper begins with an overview of the theoretical framework in the first part, and then gives an overview of how the framework can be applied to sustainability information. It concludes by suggesting the use of the framework can offer substantial insight into questions of sustainable policy development. While the approach described offers the potential to better understand organizational decision-making dynamics, the true value of the framework will lie in its future use to both predict and assess the relationship between sustainable outcomes and related decision-making processes.
\end{abstract}

Keywords: Information Processing, Public Policy, Sustainability, Decision-making.

\section{Introduction}

Understanding causal relationships between sustainability and public policy is critical for the achievement of future sustainability goals. Public policy is, by definition, a reflection of what governments do, what they choose not to do, and why they make such choices (Dye, 2011). By implication, principles of sustainability fit within the context of public policy by focusing decisions through a lens of generally accepted sustainability principles (WCED, 1987; Gladwin, Kennelly \& Krause, 1995; McManus, 1996, Naess, 2003; McGregor, 2004; Williams \& Millington, 2004). For example, if a government policy direction results in what may be defined as a 'sustainable outcome,' then we might want to identify the drivers of this outcome to determine if sustainable principles were part of the reason for this outcome.

A more complete understanding of sustainable policy implementation would include a general consideration of sustainability principles surrounding every decision made that commits public resources. Thus, a focus on the process of policy development is a critical component to understanding whether sustainable principles are being considered at the beginning, during, and at the conclusion of governmental decision-making. One important way to follow this process is to focus on the flow of information, or the way in which sustainable information is being handled through a decision-making process.

Focusing on information flows as a way of measuring the consideration of certain principles, like sustainability, is a relatively new technique in public policy analysis. Traditional theories in public policy fail to take full account of the importance of information flow dynamics; especially how discrete pieces or categories of information drive policy formation and change. Information processing provides a framework from which policy dynamics can be assessed based on how dynamics within the supply and processing of information affect policy outcomes. The particular dynamics this paper focuses on is the identification of what prevents, or limits, certain types of information from moving forward in a policy-related decision-making process. The focus on limits presents a major assumption at the heart of this theoretical approach, which is, effective sustainability outcomes in policy is dependent on the ability to meaningfully process information flows. Thus, when sustainable information is present but it is not meaningfully being made part of the decision-making process, one would tend to find limited sustainable policy outcomes. Or, if 
sustainable outcomes are present, the reason is not directly related to the sustainable information surrounding the issue.

This paper attempts to accomplish two goals. First, it sets out the theoretical framework of information processing, discussing its' basic elements and showing how its' focus on information flows can add value to understanding policymaking dynamics. Second, the paper analyzes how information processing can be used to better understand sustainability dynamics during a formal government policy formation and implementation process. This method of analysis offers both analytical and applied value because it presents a framework that can aid in determining when a principle such as sustainability may have been devalued or even abandoned during a decision-making process. Further, it offers in-depth analysis into the dynamics surrounding a category of information, allowing a deeper understanding of how such information is impacting policy directions. By focusing on information flows, one can discern the factor(s) occurring at the particular shift in information flow, thereby highlighting the most likely influences responsible for change. This paper now moves into an explanation of the theoretical framework underlying information processing.

\section{Theoretical Framework of Information Processing}

The purpose of this section is to set forth the theoretical framework of information processing, and to discuss its basic elements. To aid in understanding the written explanation that follows, a visual rendering of how information is analyzed under this theory is shown in Figure 1.

To summarize, information processing follows the flow of information through a set of categories or filters that information normally interacts with throughout a decision-making process. As a preliminary matter, the flow of information takes a particular path depending on whether the focus is on interaction with an individual or larger organizational context. Because we are dealing with sustainable information as it flows through a public institutional process, the focus here will be on the information flowing through an organization rather than individual processing considerations.

From the organizational context, information processing suggests the manner in which the organization processes information flow will largely limit the choices available to decision-makers. Thus, at the outset of organizational processing, emphasis is placed on two considerations: the supply of information, and the prioritization of information.

\subsection{Supply of Information}

Information processing borrows heavily from aspects of behavioral theory, suggesting the way decisions are made is dominated by attention, emotion, and habit (Simon, 1947, 1983). It further assumes decisions are limited by the capacity of the individual or organization to process information (Deutsch, 1963). Bounded rational theory adds another layer of analysis, focusing on how decision-making is constrained. This theory links the ability to make decisions to three main factors: (1) the information made available; (2) the cognitive limits of the decision-making body; and (3) the finite amount of time available to make decisions. Information processing embraces these limitations in decision-making, focusing on how these factors impact overall decision-making dynamics (Workman, Jones \& Jochim, 2009).

Under information processing, organizations are assumed to have a limited decision-making capacity at some level of aggregation (Jones, 2001). The purported reason for this organizational capacity limit is based on a fundamental assumption that information is generally oversupplied, especially in public policy settings. Because of this oversupply of information, political institutions are forced to focus on prioritization, or choosing what information to focus on, as a mean of dealing with information oversupply. In instances where the assumption of oversupply of information does not hold true, sufficient capacity to deal with information can allow organizations to focus attention searching for relevant information to aid in making decisions. When this occurs, the organization is presumed to be efficient regarding its information processing capacity.

In instances where information is oversupplied, organizations tend to exhibit limits on their ability to respond to information (Jones, 1994). This can be caused by a number of factors including: limits in funding; the institutional structure present; accepted rules limiting response; and norms or routines of the organization built up over time.

To summarize then, the supply of information impacts organizational behavior in handling information in the following ways. When the supply of information is limited, organizations are more capable of handling the information from a capacity standpoint. In such cases, we can expect the organization to spend time searching for relevant information and analyzing that information to aid in making informed decisions. Alternatively, where information is oversupplied, organizations are likely to be preoccupied with information processing, when the emphasis is on prioritizing the information. The bigger the information capacity of the organization, the more 
capable it is of handling larger quantities of information. However, even organizations with large information processing capacity experience limits based on the quantity of information flowing into the organization at any given time. Thus, organizations may be least efficient at handling information flows when the issues presented have greater political significance.

\subsection{Prioritization of Information}

Prioritization of information is an important consideration in information processing because it is assumed the way information is prioritized by organizations impacts the agenda setting state of public policy in significant ways. For example, unlike the traditional view of agenda setting, which tends to view information following the setting of an agenda, information processing suggests agenda setting is a response to incoming information - the information is driving the setting of an agenda rather than being created from a set agenda (Workman, Jones \& Jochim, 2009). Thus, by thinking of information as a driver of attention, determining what information actually makes its way to final decisions becomes an important question for analysis because it is this filtered information that will form the basis of decision-making. Prioritization of information is thus important because it focuses attention on how institutions respond to information flows. Moreover, if we assume there is generally more information available than a particular institution has the capacity to deal with, then prioritization becomes an especially important consideration.

There are two ways in which information can be prioritized under information processing (Simon, 1983; Jones, 1994). The first way is when information is processes serially, meaning there is only capacity to deal with a single stream of information at one time. No matter how much information is available to an organization, it only has the capacity to prioritize information in a single stream. Thus, serial processing generally results in what may be referred to as a 'first-come, first-serve' processing response, meaning the first set of information deemed valuable to the organization will tend to take precedence over later streams of information regardless of the difference in relevance of the information between the earlier and later streams.

The second type of prioritization that can occur is known as parallel processing. Parallel processing refers to an organizations capacity to handle multiple streams of information simultaneously. Unlike serial processing, where an organization is limited to handling information as one continuous stream, organizations that parallel process can handle information in multiple streams simultaneously. Thus, parallel processing allows organizations capacity to interact with lots of information by dividing the information into multiple streams, and then processing the streams as subsets of information.

Characteristics of parallel processing include: (1) the delegation to experts and issue specialists; (2) observed stability in the policy dynamics of the institution; (3) incremental adjustments to existing policy structure; and (4) the use of bargaining as a means of prioritizing the information flows (Workman, 2008). These characteristics suggest organizations capable of handling information are more likely to show patterns of stability in policy decisions. We would also expect a balance between new information and the institutional response to the information allowing for new information to be processed by the organization. This would not be expected where public entities were engaging in serial processing, which leads to an aggregation of information due to the organizations inability to keep up with the volume of information.

It is important to note that the ability to parallel process information alone is not conclusive proof of good agency decision-making. For example, even when institutions are engaged in parallel processing (they have the capacity to handle large information flows), there can still be observed failures in the system. Failures can include errors, or the non-response of governing systems to new signals of information in the policy agenda (Workman, 2008). Reasons for such failures may include: (1) the attention on a particular issue is high (often referred to as a focusing event), forcing the organization to engage in serial processing; (2) the time to react to an issue is shortened, making it difficult for information to be meaningfully processed; and (3) a lack of funding or other resources causes a limit to parallel processing capacity. There are examples in the literature where focusing events and policy failures can be correlated directly to failures in parallel processing by an organization (e.g., Birkland, 2006). In addition, the internal workings of an organization can lead to error accumulation in information processing, resulting in a mismatch between the information presented and actual policy direction (Jones, Sulkin \& Larsen, 2003).

\subsection{Institutional Dynamics - Institutional Friction}

Institutional friction refers to conditions that limit information flow and processing within an institution beyond the capacity issues described above. These conditions occur for various reasons, generally centered around how organizations choose to handle information. For simplicity purposes, institutional friction can be divided into two phenomena for descriptive purposes, bottlenecking and cognitive limits. 
Bottlenecking describes a condition where the attention limits in an institution require a limiting of the issues available for review to the few that will receive attention (Kingdon, 1984). It is based on the aforementioned premises under information processing of limited attention and information oversupply. As a result of bottlenecking, one would generally expect institutions to over respond to some issues, and under respond to others. This has been seen in case studies where institutions have been shown to amplify attention towards specific issues at certain times, resulting in a dampening of attention towards other issues (May, Workman \& Jones, 2008). It is thought that one of the main causes of bottlenecking is the lack of ability to keep up with a continuing flow of information. This can be due to an inability to process information in parallel, which itself can be brought on by the factors mentioned above (heightened attention to a singular issue, limited reaction time, lack of funding).

Cognitive limits, the other phenomena of institutional friction, focuses on the inner workings of an organization that cannot be altered through 'capacity' adjustments (Note 1). Factors affecting the inner workings of an organization include the following: (1) the rules governing the institution; (2) the norms by which the institution operates; and (3) the routines of the institution. Depending on the influence of these factors, organizations can become unable to quickly respond to new information, a condition often referred to in the literature as rusty gears. The implications can include a disproportionate response to information dynamics, sometimes referred to as error accumulation.

Institutional friction analysis considers an overt analysis focusing on the capacity of the institution to handle information supply, as well as a more internal analysis of the cognitive limits of the institution. This type of analysis can aid in detecting the existence and evolution of errors, which are mismatches between the information available for consideration and the information actually being considered by an organization. By identifying the existence of errors, insights can be gained into the dynamics of organizational decision-making, including detailed insights into how information is being handled by the organization.

\subsection{Error}

Error in information processing describes the relationship between information signals, and the ability of an organization to respond to this signal. Error is calculated by determining the extent of disconnect between the information signals and what information the organization is processing. Where there is a proportionate response from the institution to new signals in the policy environment, error will be low. Conversely, where this is a disproportionate response by the institution to information signals in the environment, errors will accumulate. Accumulation of error over time can lead to phenomena such as a punctuated policy change, shown where an organization makes a sudden shift in policy direction as it tries to resolve the disparity between information in the environment and the organization's lack of response to that information.

The accumulation of errors under information processing is generally related to institutional dynamics. Causes of error are assumed to be either limited attention of the organization, or institutional friction within the organization. Limited attention describes the inability of an organization to focus on available information, which can be caused by a variety of factors. For example, institutions busy fixing one set of errors has a limited capacity to respond to other issues, allowing errors to accumulate. Institutional friction refers to the inability of an organization to respond to small changes in information because of the varied intra-institution dynamics discussed previously. In either example, what is common is the general assumption that organizations operate with a limited capacity to focus on problems. When attention is limited, the oversupply of information cannot be adequately processed, reinforcing the phenomenon of errors until some specific action is taken to resolve the error. Understanding how this limited attention relates to error accumulation, and also how errors are ultimately dealt with by an organization can add significant insights into policy development, implementation, evaluation and change.

\subsection{Quality of Information}

Up to this point, the conceptual framework described above has focused on the quantity of information, describing how organizational capacity impacts the ability to handle large volumes of information. This portion of the framework focuses more closely on the quality of information available to an organization. The actual quality of the information is usually determined by analyzing the source of the information. For example, if the source of the information is deemed independent, perhaps an academic institution with independent funding, then the information may be of potentially higher quality than other sources of information with a less reputable background or rigorous process.

Information may also be filtered to determine an original source. By analyzing the source of the information, the overall quality of the information being presented to an organization may be determined. The institutional response to different types of information can then be determined, not just information quantity dynamics as described above. For example, is an organization capable of filtering between high and low quality information? If it is, does it regularly accept higher quality information over lower quality information, especially in cases where information is 
being oversupplied and the organization is limiting their focus to portions of the information stream? The purpose of this type of inquiry is to follow the information through the institutional filtering process to determine whether it is actually making its way to decision-makers, or in other words, whether the valuable information signal is being seriously considered in the policymaking process. The dynamics of the organization will either aid or hinder quality information from making its way to the agenda setting stage of policy formation.

\subsection{Delegation and Information Processing}

In systems of government, like the United States, where political outputs (laws) are often delegated to Executive Branch agencies for implementation, it is important to review how those administrative entities handle information as part of their implementation process. The reason is these government entities are chiefly responsible for policy implementation, which includes the development of sub-policies. Thus, reviewing their information processing dynamics can aid in understanding the degree to which certain information is making its way into a policy agenda, whether by direct implementation of a legislative mandate, or indirectly through the development of policy by the administrative entity.

One way to understand this process is to view administrative bodies as filtering mechanisms that identify potential issues for policy consideration. This is somewhat contrary to the traditional view of legislative delegation, which suggests administrative institutions are created as a response to focused attention on an issue for the legislative or executive branches of government (McCubbins, 1985; Wood, 1988; Wood \& Waterman, 1994). Under this traditional view, administrative bodies are created to respond to issues, not to detect and initiate issues. However, if we view administrative institutions as the monitors of the policy environment to detect potential problems through information signals (Feldman \& March, 1981), then we may see administrative bodies are also acting as issue drivers by supplying decisionmakers with relevant information from which attention is given. From this perspective, administrative bodies may also be seen as monitoring and attention-directing organizations (Arrow, 1974; Workman, 2008).

The purpose of analyzing administrative bodies in this way is to see bureaucratic organizations as both monitors of the environment for the purposes of information collection, and as filters of this information by engaging in the processing of this information. The implications are profound. For example, policymakers may actually be relying on administrative bodies as the supplier of relevant (filtered) information to aid in decision-making. Thus, under this subset of information processing , administrative entities are treated as potential searches and filterers of information from the environment. Moreover, they are seen as playing a role in influencing decisions either directly, by making policy-relevant decisions (through delegation for example), or indirectly by determining the information that is actually relied upon by decision-makers when engaging in policymaking. In this context, the role of administrative entities can be substantial.

\section{Information Processing Applied to Questions of Sustainability}

Now that the conceptual framework for information processing has been defined, it needs to be placed into the context of sustainability. Specifically, what role might information processing serve as an analytical tool in helping to better understand how issues of sustainability are being handled by government entities?

As suggested from the theory itself, focusing on information flows can allow one to follow specific information through an organizational process. By focusing on the information flow, it can be observed if information is making its way through an entire decision-making. For example, the issue of fishery by-catch has often been linked to questions surrounding sustainability (Note 2). Specifically, excessive by-catch can be argued to impact the overall health of the marine ecosystem. One remedy might include a limit on the amount of by-catch based on evidence supporting the link between by-catch rates and sustainable fishing practices. To determine if this principle is actually considered in setting new fishing standards (including potential restrictions), the information relating to by-catch could be followed through the governmental process. If the information fails to fully inform the process at the final decision stage, then focused attention could be placed on observing where the information resides in the process to try and determine what actions, or inactions, resulted in a failure of the information to fully inform the decision-making process. This same methodology could be applied to almost any government decision-making process dealing with questions of the environment in general, and sustainability in particular.

Sustainability goals are often touted in the political arena, especially when these issues are highlighted through public sentiment and support. However, few political outcomes actually integrate sustainability principles into the operational end of government functions (Dovers, 2005). This would tend to suggest that sustainability, while supported in theory by both the public and politicians, fails to find its way into a more meaningful representation of government function. Understanding exactly why this occurs can aid in a clearer implementation of sustainability strategies by understanding the dynamics of the process. Information processing provides an analytical tool to 
determine how sustainability-related information is being handled during this process.

\subsection{Government Implementation of Sustainability}

Governments often publicly support sustainability goals. A prime example is the general consensus amongst nations on making efforts to mitigate the impacts of climate change (IPCC, 2007). However, this public support is often limited to actions that do not require mandatory commitments. A lack of mandatory commitments taken by governments related to climate change is but one example. When sustainability principles are strongly implemented in government policy, they are usually of secondary importance, meaning the policy had a primary goal unrelated to sustainability, but that primary goal contained secondary effects that achieved sustainable outcomes. For example, many of the federal environmental laws passed in the United States during the 1970s contained language identifying sustainability as a goal of the particular legislation (Note 3). However, these goals were secondary to the primary purpose of protecting the immediate public health (Firestone, 2008, p. 20-25). While some argue protecting public health is tantamount to sustainability, the long-term nature of generally accepted definitions of sustainability are not an integral characteristic in protecting the public health (Note 4).

It is often difficult, to near impossible, to understand the role sustainability plays in public decision-making because of the dynamic nature of the policymaking process. Is sustainability playing a primary role in government decisions, or are sustainable outcomes in government policy generally a result of secondary effects? One way to begin answering this question is to follow information flows related to sustainability, and see how this information works its way through the policymaking process. Further, following sustainable information flows over time can aid in showing how government priorities relative to sustainability might be changing. For example, initial research might show Government A tends to diminish the role of sustainable information in a certain category of decisions. However, over time Government A is shown to utilize sustainable information as a primary reason for setting policy goals. When this is observed, it may be concluded that Government A is relying more on sustainable information as a driver of decisions in particular policy arenas rather than, for example, using sustainable information as additional support towards an unrelated policy agenda.

\subsection{The Importance of Defining Sustainable Information Clearly in Information Processing}

How one defines sustainable information is a crucial to engage in accurate information processing. If information processing is about following specific information flows to determine the use of that information, then it is rationally critical to determine what types of information constitute sustainable information. Otherwise, an analysis may follow improperly categorized information, yielding inaccurate results under this theory. Thus, properly defining sustainable information is a key step in accurate information processing.

Sustainable information is more categorical, or topical, than it is specific. In other words, a lot of different types of information might be categorized as sustainable depending on one's definition. This is different then, say, following a discrete piece of information through a government decision-making process; one example might be information about a specific endangered species. The information is discrete to the species itself, and it is generally easy to analyze whether this information makes its way to the final decision-making stage of a government unit. Sustainable information may include information about a specific endangered species, but this is highly dependent on how one defines the sustainable information at issue in the particular decision-making process. A lax definition may lead to inaccurate results when analyzing the information flow. For example, the analysis might focus on information that is, in retrospect, not entirely tied to sustainable outcomes. In so doing, inaccurate results about the use of sustainable information in the decision-making process (especially judgments about the priority of information) can result. Thus, in order for this theoretical approach to yield practical results and insights, a thorough methodology must be adhered to, beginning with a strict definition of what information is, and is not, sustainable information in a particular setting. This can be done by carefully defining sustainable information in a given setting, while also establishing specific criteria delineating what information meets the definition.

For illustrative purposes, one example might be shown where a government is establishing limits on the amount of pollution allowed from coal burning power plants. The government might specifically define pollution to include a number of chemical compounds that are present and become airborne during the normal burning of coal in a normal power plant setting. Let us say the burning of the coal creates ten different chemicals that are considered harmful to humans and the environment in certain concentrations. The government program may desire to limit all ten chemicals to protect human health. The relevant question is what limit does the government set on each of these chemicals, including what information does the government rely on when setting the limits for each chemical being regulated? The information the government chooses to rely on in setting particular limits is the critical consideration for information processing purposes. Thus, what information we choose to follow through the process is of upmost importance. Further, what information we choose to follow is impacted by how we define sustainable information in 
this particular instance.

There are a number of choices one might make to define sustainable information in this example. One might determine, as a preliminary matter, that all ten chemicals being sent into the atmosphere are important for sustainability purposes, in-line with the governments' decision to regulate these chemicals. In such a case, the information that is relevant in setting limits for all ten chemicals is necessary to follow. Now, during this process there is likely to be competing information. Some information may tend to support a lower overall allowance of a particular chemical, while other information might tend to support a higher overall allowance of that same chemical. A critical choice must be made here as to which information leads to a clearer definition of sustainability. For example, using a precautionary approach, one might determine the information supporting a lower allowance of the chemical is closer to a particular definition of sustainability, and thus presents the information that should be followed. Conversely, one might find the information supporting the higher allowance to be sufficient for sustainability goals. Where information supporting a higher allowance meets requirements for sustainability, it is likely the information supporting lower limits also supports sustainability. Thus, in this case, the 'filter' for information would be any information provided to support limits in some fashion.

What particular information meets the definition of sustainability will impact the overall information processing as a means of determining the use of sustainable information in the decision-making process. Using the example above, if a precautionary definition of sustainability is used, and the lower allowance is deemed to only meet sustainable outcomes, then the use of that information in the final decision-making process will help us understand whether sustainable information is being used to make the decision. Where a decision is based on that information directly, and lower allowances are in-fact set by the government body, then we can conclude sustainable information was a part of the decision-making process. However, if the lower allowance information is discounted early on in the decision-making process, and it does not make its way to the final decision-making stage, then we can conclude sustainable information did not play a primary role in the governments' final decision-making. If we include the higher allowance in our definition of sustainability, then the government's discounting of the lower allowance would not matter, as we would ultimately conclude the government was still using sustainable information in its' final decision-making process. Thus, through this example, we can begin to see how an exact definition of sustainability is critical in properly applying information processing as described above.

The example provided immediately above is purposefully simple to show the important nature of general definitions. The example does not provide the necessary rigor of establishing the reasons, or criteria, by which certain information might be deemed sustainable, while other information might be excluded from being categorized as sustainable. However, even in its' simplicity, the example provides sufficient context for understanding the importance of properly labeling the information being followed. This brings up a final point about the importance of using information processing theory to identify and follow government implementation of sustainability principles, namely the rigor applied to defining and following flows of sustainable information. This process requires adherence to a detailed methodology for precisely establishing what is meant by the term sustainability in a particular context. The value here is that by engaging in this process, there can be no doubt as to what is being labeled as sustainable information, as well as the rationale that is being employed to justify the label being placed on specific information.

One major criticism often leveled at the field of sustainability studies, especially in the social science context, is the inability to adequately define sustainability in context (McManus, 1996; Millennium Ecosystem Assessment (2005); Ehrlich \& Ehrlich, 2009). What has been argued here is that information processing theory can only work when the information being followed is accurately labeled through a rigorous process that includes establishing the criteria by which the information is meeting the stated definition. Thus, in its' very methodology, information processing theory offers a preemptive defense against one of the more common criticisms of sustainability studies. In doing so, it offers a potentially superior means of analyzing public policy actions to determine the manner and impact sustainability information is having on the decision-making process.

\subsection{Information Processing and Government Accountability}

Information processing may be seen as a transparent system of accounting applied to government decision-making. This is especially true in the field of sustainability, where it is often difficult to discern how government is reacting to information affecting questions of sustainability Williams \& Millington, 2004; Bell, 2009). The theoretical process laid out in the preceding sections aims at identifying how this transparent accounting system might work. In this section, some summary explanations are given as to the potential impact this level of transparency can have on the overall efficiency of government.

Regardless of the social theory underlying any one particular government, the general consensus on the purpose of government is to provide fundamental services to its' people (Adler, 1996). Since government is often funded in 
large part by a system of taxation or levy on the income of its' citizens (Dietz, 1990), the manner in which government provides fundamental services becomes an important question. In most cases, it is argued the performance of government functions should be as cost-effective as possible to ensure integrity of the public trust (Christian, 2004).

One way of knowing whether a government is acting in a cost-effective manner is to relate the cause of government action to a response from the government, or the effect the initial cause has on governmental action (Schulze, 1994). This cause/effect relationship is admittedly not linear, meaning there are numerous variables that impact the ability of a government to respond to new information. However, by following the information itself, as is done in information processing, one can begin to decipher whether the information itself is the cause of a particular government response, or rather if other factors have influenced the final government decision or outcome. As noted in the above example, when key information has not made its way to the final decision-making process, it is likely other factors beyond this key information are influencing the final decisions being made. In reviewing government decisions, one following this type of information flow can more readily identify when these other factors might be influencing the final decision, as opposed to instances where the initial information remains the driver of the decision. In this way, information processing can offer an important analytical tool in creating a more accountable government decision-making process. At the very least, it can highlight where government decisions are focusing on the information that brings attention to an issue, and where government action is ultimately unrelated to this initial causal information. This is especially important in questions of sustainability, where the associated dynamics can limit an understanding of how sustainable information is influencing final decisions.

\subsubsection{Knowing Where Information Resides Can Inform How Information is Being Used}

As a final point in discussing the practical applications of the conceptual framework of information processing, the connection between information location and overall value being placed on that information is explained in this section.

Information processing relies on a basic tenet borrowed from the social and natural sciences that suggests we tend to use things we find relevant, and discard things we find irrelevant (Rasmusen, 2006). Applying this basic tenet to information processing, it is assumed we can know a great deal about how information is being used by focusing on where information is located in a decision-making process. For example, let us assume there are ten (10) total steps to a particular decision-making process, with each step representing an important part of the final decision. This can be visually represented as a decision tree, where each mini-decision represents a branch of the tree to the ultimate decision (Skyrms, 2004). A representation of this process is show below in Figure 2.

Let us further assume that a certain piece of information (call it information piece $A$ ) is being highlighted at the beginning of the decision-making process as a reason that attention is being drawn to this issue. Under information processing, we would want to follow this information piece $A$ throughout the entire 10-step process of the decision-making to see where the information finally resides. Say, for example, the information only makes it to step five (5) of the decision-making process. What does this say about the relevance of the information in the final decision? Well, we know it had the potential to impact the first 5 steps of the decision process significantly because it was used in each of these first 5 steps. However, we cannot easily say information piece $A$ had a substantial impact on steps 6-10 because the information was not an overt part of these steps in the ultimate decision-making process. Most importantly, we know this piece of information was not part of the final decision (step 10), and that might indicate this piece of information was discounted, and may have been a minimal to non-factor in influencing the final decision. Of course, to be sure of this, we would have to closely scrutinize the decisions in steps 6-10 to see what information may have been highlighted during these latter steps of the decision-making process. Also, we may determine steps 6-10 were influenced by steps 1-5 (which included information piece $A$ ). If this is the case, then it is possible information piece $A$ did play a role in the ultimate decision. Its' overall impact would have to be determined through a detailed analysis of the entire process.

One key insight here is to acknowledge that where the information ends up in a decision process says something about its' potential role, and thus influence, on the overall decision-making process. By closely monitoring where the information resides in a decision process, we are informed on exactly how that information is being used by decision-makers. This is yet another important application of the use of information processing.

\section{Conclusion}

The purpose of this article was to identify a conceptual framework for following information flows to determine the overall use of that information in government decision-making. The conceptual framework, information processing, was explained and the potential value of the framework was attached to questions of sustainability, although it can be applied to any category of information. It is argued this theory has special application to environmental 
decision-making, and sustainability in particular, because environmental/sustainable information is often disconnected in government decisions. What is meant by a disconnect is that the stated reasons for a government decision that are related to environmental/sustainable goals often are not part of the final government decision, meaning environment/sustainable goals are often not achieved. This is often due to a number of factors, leaving it unclear how to best determine the likelihood that government decisions will actually result in strong sustainable outcomes.

Information processing is one way to being to understand when environmental/sustainable information is influencing the decision-making process. By following a specific piece of information throughout the entire decision-making process, the overall impact that piece of information has on the final government decision can be more easily analyzed. As indicated above, where we see evidence that environmental/sustainable information is being discarded during the decision-making process, it is likely there will be limited positive impacts in these areas associated with the final government decision regardless of how that decision is labeled. Conversely, where we see evidence environmental/sustainable information is informing government decisions throughout the entire decision-making process, it is more likely the ultimate decision will impact environmental/sustainable goals.

Now that this theory has been suggested as a way of measuring environmental performance of a government unit, case studies need to be created. It is suggested this theory be used as an analytical framework from which government actions related to environmental/sustainability goals are critically analyzed. These studies will aid in understanding the overall relationship between information flows and sustainable outcomes. As these case studies increase in number, we can hope to determine the overall influence this analytical framework might have in better judging the performance of government policies that identify environmental/sustainable goals as a major purpose of the policy. The ultimate goal here is to create better accounting systems to understand how relevant information is influencing government decisions.

\section{References}

Adler, M.J. (1996). The common sense of politics. Bronx, NY: Fordham University Press.

Arrow, K.J. (1974). The limits of organization. New York, NY: Norton and Company.

Bell, M.M. (2009). An invitation to environmental sociology. Thousand Oaks, CA: Pine Forage Press.

Birkland, T.A. (2006). Lessons of disaster: Policy change after catastrophic events. Washington, D.C.: Georgetown University Press.

Christian, D. (2004). Maps of time. Berkeley, CA: University of California Press.

Clean Air Act Amendments of 1963, Pub.L.No. 88-206, 42 U.S.C. $§ 7401$ (1990).

Dietz, M.G. (1990). Thomas Hobbes \& political theory. Topeka, KS: University Press of Kansas.

Dovers, S. (2005). Environment and sustainability policy: Creation, implementation, evaluation. Sydney, AU: The Federation Press.

Dye, T.R. (2011). Understanding public policy. Portland, OR: Longman Publishing.

Ehrlich, P.H. \& Ehrlich, A.H. (2009). The population bomb revisited. Electronic Journal of Sustainable Development, 1(3). 63-71.

Feldman, M.S. \& March, J.G. (1981). Information in organizations as signal and symbol. Administrative Sciences Quarterly, 26(2), 171-186. doi:10.2307/2392467, http://dx.doi.org/10.2307/2392467

Firestone, D. (2008). Environmental law for non-lawyers. South Royalton, VT: SoRo Press.

Gladwin, T. N., Kennelley, J.J., \& Krause, T-S. (1995). Shifting paradigms for sustainable development: Implications for management theory and research. Academy of Management Review, 20, 874-907.

IPCC. (2007). Climate change 2007: Synthesis Report. Geneva, CH: Author.

Jones, B.D. (1994). Reconceiving decision-making in democratic politics: Attention, choice, and public policy. Chicago, IL: University of Chicago Press.

Jones, B.D. (2001). Politics and the architecture of choice: Bounded rationality and governance. Chicago, IL: Chicago University Press.

Jones, B.D., Sulkin, T., \& Larsen, H.A. (2003). Policy punctuations in American political institutions. American Political Science Review, 97(1), 151-169. doi:10.1017/S0003055403000583, http://dx.doi.org/10.1017/S0003055403000583 
Kingdon, J.W. (1984). Agendas, alternatives, and public policies. Boston, MA: Little Brown.

May, P.J., Workman, S., \& Jones, B.D. (2008). Organizing attention: Responses of the bureaucracy to agenda disruption. Journal of Public Administration Research and Theory, 18(4), 517-541. doi:10.1093/jopart/mun015, http://dx.doi.org/10.1093/jopart/mun015

McCubbins, M.D. (1985). The legislative design of regulatory structure. American Journal of Political Science, 29(4), 721-748. doi:10.2307/2111178, http://dx.doi.org/10.2307/2111178

McGregor, A. (2004). Sustainable development and 'warm fuzzy feelings': Discourse and nature within Australian environmental imaginaries. Geoforum, 35, 593-606. doi:10.1016/j.geoforum.2004.02.001, http://dx.doi.org/10.1016/j.geoforum.2004.02.001

McManus, P. (1996). Contested terrains: politics, stories and discourses of sustainability. Environmental Politics, 5, 48-73.

Millennium Ecosystem Assessment. (2005). Overall Synthesis, Washington, D.C.: World Resources Institute. Retrieved from http://www.marisec.org/worldtradeflyer.pdf.

Naess, A. (2003). The deep ecological movement: Some philosophical aspects (reproduced from Philosophical Inquiry 1986). In A. Light and H. Rolston (Eds.), Environmental Ethics (pp. 262-274). Oxford, UK: Blackwell Publishers Ltd.

Rasmusen, E. (2006). Games and information: An introduction to game theory. Cambridge, MA: Blackwell Publishers.

Schulze, H. (1994). States, nations and nationalism. Malden, MA: Blackwell Publishers.

Simon, H.A. (1983). Reason in human affairs. Stanford, CA: Stanford University Press.

Skyrms, B. (2004). The stag hunt and the evolution of social structure. New York, NY: Cambridge University Press.

WCED. (1987). Our common future: World commission on environment and development. Oxford, UK: Oxford University Press.

Williams, C.C., \& Millington, A.C. (2004). The diverse and contested meanings of sustainable development. Geographical Journal, $\quad$ 170, 99-104. doi:10.1111/j.0016-7398.2004.00111.x, http://dx.doi.org/10.1111/j.0016-7398.2004.00111.x

Wood, D.B. (1988). Principals, bureaucrats, and responsiveness in clean air enforcements. American Political Science Review, 82(1). 213-234. doi:10.2307/1958066, http://dx.doi.org/10.2307/1958066

Wood, D.B. \& Waterman, R.W. (1994). Bureaucratic dynamics: The role of bureaucracy in a democracy. Boulder, CO: Westview Press.

Workman, S. (2008). Setting the agenda: Bureaucratic influence in problem definition. Working Paper, Austin, TX: Policy Agendas Project.

Workman, S., Jones, B.D., \& Jochim, A.E. (2009). Information processing and policy dynamics. The policy studies journal, 37(1), 75-92. doi:10.1111/j.1541-0072.2008.00296.x, http://dx.doi.org/10.1111/j.1541-0072.2008.00296.x

\section{Notes}

Note 1. An example of a capacity adjustment would be increasing funding to provide additional resources to the organization for processing information flows.

Note 2. The term by-catch refers to non-target species of marine life that are inadvertently caught during the process of fishing for a particular species. For example, if a fishing vessel is using a net to catch Target Species A, and it also catches Non-target Species B, Species B would represent by-catch of the fishing vessel.

Note 3. For example, the Clean Water Act of 1972, in section 1251(a) contains language indicating a goal of the statute to the restoration and maintenance of the chemical, physical, and biological integrity of the waters of the United States. This language clearly includes goals related to sustainability, or maintaining the integrity of the water for the foreseeable future (i.e., for future generations).

Note 4. For example, protecting against airborne emissions of pollutants might include the use of best-available technologies to limit the airborne pollution. This is, in fact, what is generally done to regulate stationary source of pollution under the United States Federal Clean Air Act (Clean Air Act, 1990). While this action tended to control harmful criteria pollutants in the atmosphere, which can impact long-term effects of air quality for future generations, the policy choice of best-available technology allows the continuation of the burning of fossil fuels. 
Any rationale definition of sustainable energy policy cannot contemplate the long-term use of fossil fuel burning as allowed in the Clean Air Act. Thus, the policy cannot be said to be sustainable in the true sense of the term, even though in comparison to no regulation the implementation of technology controls has an impact on air quality over the long term. A more direct example of sustainable energy policy would be if the Clean Air Act prevented the use of fossil fuels for energy production and rather required the use of renewable sources of energy, such as wind or solar sources of energy production.

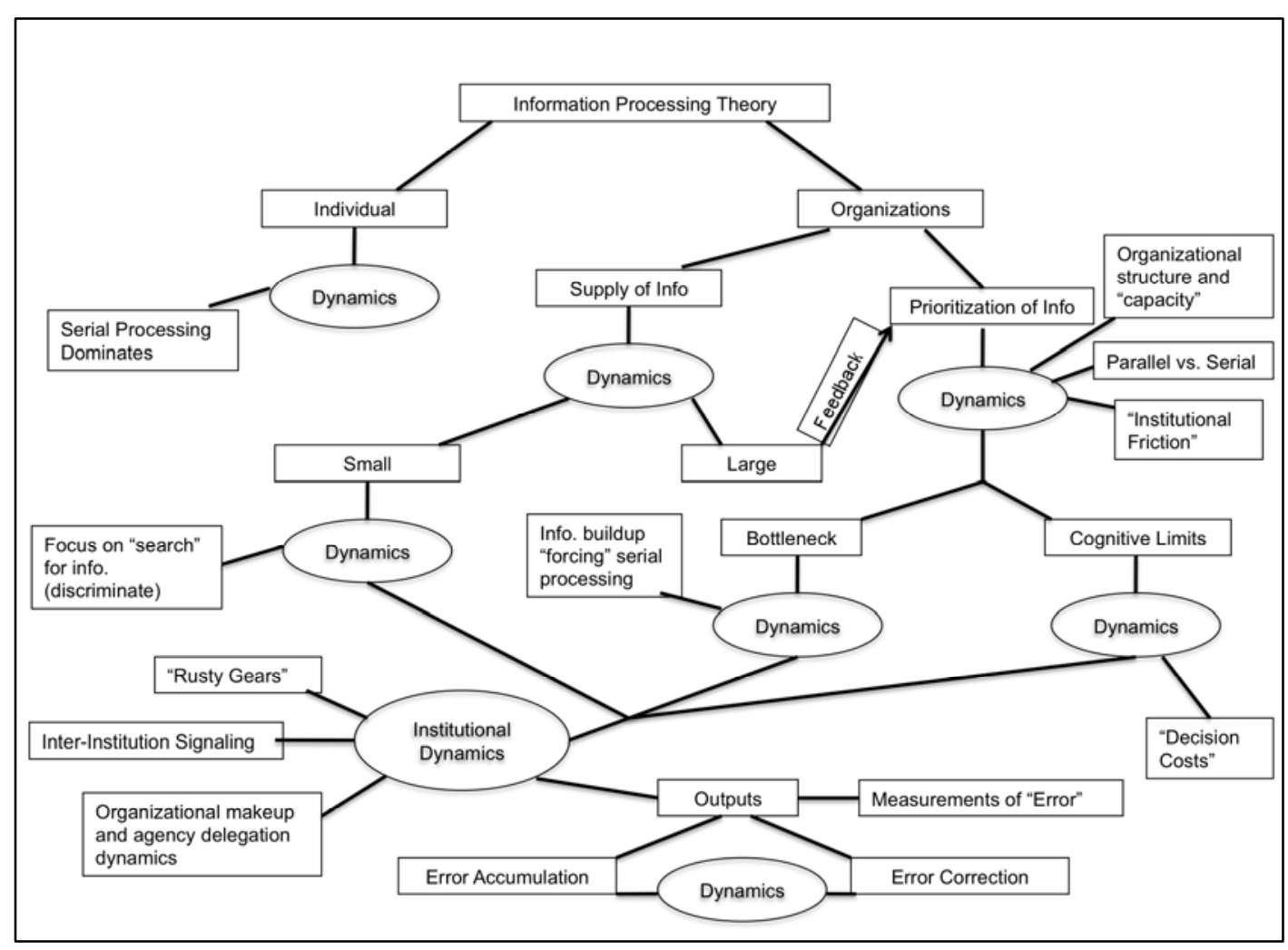

Figure 1. Visual Rendering of Information Processing Theory Framework

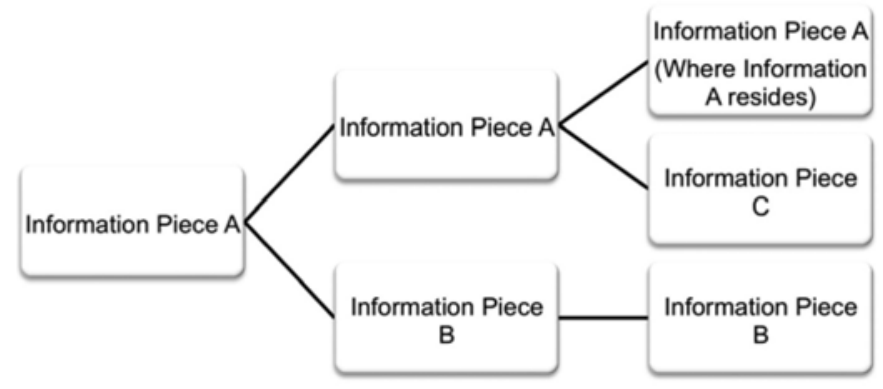

Figure 2. An example of a decision tree.

Notice how Information Piece A travels along the upper-portion of the decision tree. After the initial decision, it no longer is part of the lower portion of the decision-making process. This suggests the information in piece A would no longer be available as a driver of decision-making if the decision-making process were to move along the path indicated by Information Piece B. 